\title{
Development of para rubber seed oil as the efficient makeup remover
}

\author{
Nattaya Lourith ${ }^{\circledR 1,2, *}$, Mayuree Kanlayavattanakul ${ }^{1,2}$ \\ ${ }^{1}$ School of Cosmetic Science, Mae Fah Luang University, Chiang Rai, Thailand, ${ }^{2}$ Phytocosmetics and Cosmeceuticals Research \\ Group, Mae Fah Luang University, Chiang Rai, Thailand
}

\begin{abstract}
The para rubber tree (Hevea basilensis) is an economically important tropical tree species that produces natural rubber, a valuable industrial raw material. Innovative products that are derived from by-products from the rubber production process, such as seeds, are important for the sustainability of the para rubber industry. Therefore we subjectively assessed para rubber seed oil for its makeup-removal efficacy and developed it into a makeup cleansing product with appropriate quality control measures for the cosmetic industry. The makeup-removal efficacy of para rubber seed oil was analyzed using a validated UV-Vis spectroscopy, which indicated that the oil removed $86.21 \pm 2.48 \%$ of liquid foundation [relative standard deviation $(\mathrm{RSD})=2.88 \%$ ]. Therefore, we developed stable makeup removers containing $40-70 \%$ para rubber seed oil. Bio-oil removers containing 50\% and 60\% oil had the best appearance and texture and were subsequently evaluated for their makeup-removal efficacy. The bio-oil remover with the higher oil content was significantly better at removing makeup $(95.26 \pm 0.97 \%$ removal by the $60 \%$ oil compared with $73.88 \pm 3.97 \%$ removal by the $50 \%$ oil). To conclude, para rubber seed oil is a promising new bio-oil for the cosmetic industry, which broadens consumers' choices of bio-oil makeup removers. We believe that the manufacture and quality control of this innovative and efficient makeup remover are feasible on an industrial scale.
\end{abstract}

Keywords: Para rubber. Bio-oil. Color cosmetics. Makeup remover. Cleansing efficacy.

\section{INTRODUCTION}

Crop waste from various agricultural operations is continuously increasing each year, which has resulted in unsustainably high economic and environmental management costs. Consequently, it has become imperative to investigate conversions of agricultural wastes into specialty ingredients or innovative products (Lourith, Kanlayavattanakul, Chingunpitak, 2017a; Lourith et al., 2017b).

Para rubber is an important raw material that is used for the manufacture of $>40,000$ products (Kadir, Jantan, 2016). Thailand is one of the three major para rubber production countries in the world (Nair, 2010). Innovative sustainable products derived from rubber production by-products are already contributing to the value chain of the para rubber industry, e.g. tree trunks

\footnotetext{
*Correspondence: N. Lourith. School of Cosmetic Science, Mae Fah Luang University, Chiang Rai 57100, Thailand, Phytocosmetics and Cosmeceuticals Research Group, Mae Fah Luang University, Chiang Rai 57100, Thailand. Tel.: +66 53 916834; Fax: +66 53 916831. E-mail address: nattayal@mfu.ac.th
}

are used to manufactur products for the wood furniture industry.

In addition, para rubber seed oil can be used for bio-fuel production (Ikwuagwu, Ononogbu, Njoku, 2000; Ramadhas, Jayaraj, Muraleedharan, 2005) and animal feed (Gandhi, Cherian, Mulky, 1990). Extraction of the oil with $n$-hexane using a Soxhlet apparatus has been reported to yield a bio-oil with promising antioxidant activities for use in cosmetic products. This bio-oil is not cytotoxic to human skin fibroblasts and is rich in bioactive fatty acids that are essential for cosmetic applications. Further, its physicochemical properties are similar to those of vegetable oils that are commonly used components of many cosmetic formulations (Lourith et al., 2014). Additionally, the use of $n$-hexane as an extracting solvent is feasible for industrial practice owing to its ease of recovery and the quality of the recovered solvent, which can be then reused (Lourith et al., 2016).

Facial makeup products are commonly used to improve social attractiveness and the users' self-esteem. Water-resistant products are in high demand, although 
they are more difficult to remove. Consequently, there is a requirement for the development of more robust makeup removers, and these are widely supplied with waterresistant makeup products (Lourith, Kanlayavattanakul, 2014). Efficient bio-oil-containing makeup removers particularly meet consumers' preferences.

UV-Vis spectroscopic methods are regarded as feasible and reliable methods for the routine evaluation of makeup remover efficacy in vitro as well as for use during the process of product development (Charoennit, Lourith, 2012; Lourith, Kanlayavattanakul, 2014). Therefore, in an integration of the agricultural and cosmetic industries, para rubber seed oil was comprehensively assessed for its makeup removal efficacy and developed into a makeup cleansing product with appropriate quality and safety for the cosmetic industry.

\section{MATERIAL AND METHODS}

All the solvents and reagents used in the analyses were of analytical grade, whereas all solvents and reagents required for the cosmetic formulations were of cosmetic grade.

\section{Preparation and fatty acid analysis of para rubber seed oil}

Seeds from the para rubber tree (Hevea basiliensis) cultivar RRIM 600 from plantations in Chiang Rai, the northern province of Thailand, were obtained from a farm situated close to Mae Fah Luang University. The seeds were dried in a hot air oven at $45^{\circ} \mathrm{C}$ for $30 \mathrm{~min}$, ground into powder, extracted with $n$-hexane using a Soxhlet apparatus, and concentrated to dryness in vacuo. The fatty acid composition of the resulting oil was determined by converting all fatty acids to fatty acid methyl esters (FAMEs) followed by GC-MS analysis. The oil, resuspended in toluene (J. T. Baker, USA), was mixed with $\mathrm{MeOH}$ (Merck, Germany) and $8 \%$ (v/v) $\mathrm{HCl}$ (VWR, USA), and incubated at $45^{\circ} \mathrm{C}$ for $24 \mathrm{~h}$. The methyl esters were extracted with $n$-hexane, and the $n$-hexane layer was dried over anhydrous $\mathrm{MgSO}_{4}$ (Panreac, Spain). GC-MS analysis was performed on an Agilent (USA) $6890 \mathrm{~N}$ gas chromatographed equipped with an Agilent HP-5MS capillary column $(30 \mathrm{~m} \times 250 \mu \mathrm{m}, 0.25 \mu \mathrm{m}$ film thickness $)$ and coupled to an Agilent $5973 \mathrm{~N}$ mass spectrophotometer. Helium was used as a carrier gas in constant flow mode ( $1.0 \mathrm{~mL} / \mathrm{min}$ ). The FAME sample $(1 \mu \mathrm{l})$ in $\mathrm{CH}_{2} \mathrm{Cl}_{2}$ (VWR) was injected $\left(220^{\circ} \mathrm{C}\right)$ into the system in the splitless mode. The oven program was started at $50^{\circ} \mathrm{C}(5 \mathrm{~min})$, increased to $65^{\circ} \mathrm{C}$ at a rate of $2{ }^{\circ} \mathrm{C} / \mathrm{min}$, then increased to $200^{\circ} \mathrm{C}$ at a rate of $5{ }^{\circ} \mathrm{C} / \mathrm{min}$ and held at $200^{\circ} \mathrm{C}$ for $5 \mathrm{~min}$, and finally increased to $250{ }^{\circ} \mathrm{C}$ at $10^{\circ} \mathrm{C} / \mathrm{min}$ then held at $250{ }^{\circ} \mathrm{C}$ for $10 \mathrm{~min}$. The reference mass spectrum was obtained from the MS-Willey7n.1 database (Lourith et al., 2014).

\section{Validation of the in vitro cleansing efficacy of para rubber seed oil}

The specificity, linearity, accuracy, and precision of liquid foundation (Colorstay, Revlon, USA) removal by para rubber seed oil were examined using a method previously described (Charoennit, Lourith, 2012; Lourith, Kanlayavattanakul, 2014; Parnsamut, Kanlayavattanakul, Lourith, 2017). The oil (0.080 g) was accurately weighed in a conical flask using an analytical balance (SI-234, Denver, USA). Ethanol (95\%, Labscan, Ireland) was then added $(40 \mathrm{~mL})$, and the mixture was sonicated (690DAE, Crest Ultrasonics, Malaysia) for $2 \mathrm{~min}$. The mixture was subsequently filtered through Whatman no. 1 filter paper into a $50 \mathrm{~mL}$ volumetric flask, and the filtrated was adjusted with additional $95 \%$ ethanol to achieve a final volume.

For the specificity validation, the sample was analyzed using a LibraS22 UV-Vis spectrophotometer (Biochrom, UK), and a specific wavelength was chosen for the analysis of the liquid foundation. Subsequently, the absorbance of a dilution series of the liquid foundation (0.5200-1.4200 mg/mL) was recorded at this specific wavelength. The linearity was determined, which gave a coefficient of determination of $>0.995$.

The accuracy of the analytical conditions was validated by absorbing the liquid foundation $(0.035 \mathrm{~g})$ into a stack of four square $(2.5 \times 2.5 \mathrm{in})$ cotton sheets (Canton Medicare, Thailand), extracting the foundation from the sheets (using $4 \times 10 \mathrm{~mL}$ ), filtering the extracts as described above, and adjusting the final volume to $50 \mathrm{~mL}$ with $95 \%$ ethanol prior to recording the UV-Vis absorbance. The recovery (\%) of the extracted makeup was then calculated. The precision of the analytical method was assessed as follows: liquid foundation $(0.035 \mathrm{~g})$ was applied onto a clean glass plate $(3 \times 3 \mathrm{~cm})$, and the remover oil $(0.080 \mathrm{~g})$ was added. The glass plate was wiped with a stack of 4 cotton sheets $(2.5 \times 2.5$ in) four times (top to bottom, bottom to top, left to right, then right to left). The foundation was then extracted from the wiped cotton and spectroscopic analysis was performed as described above.

All data were expressed as the mean \pm RSD. The recovery data and \%RSD were compiled according to the Association of Official Analytical Chemists (AOAC International, 2002), the International Council for Harmonisation of Technical Requirements for Registration of Pharmaceuticals for Human Use (ICH, 2005), and the 
United States Food and Drug Administration (USFDA, 2001) guidelines.

\section{Formulation of an efficient and stable para rubber seed oil makeup remover}

Cleansing products containing para rubber seed oil were then formulated. These contained PEG-20 glyceryl triisostearate, ethylhexyl palmitate, neopentyl glycol diheptanoate (and) isododecane, capric/caprylic triglyceride, tocopheryl acetate, and a fragrance (Namsiang, Thailand). The $\mathrm{pH}$ of $10 \%(\mathrm{v} / \mathrm{v})$ solutions of the formulations were measured using a Lab850 $\mathrm{pH}$ meter (Schott, Germany). Sensory evaluation during the course of product development was performed by observing colors, odors, and textures. In addition, the cleansing ability of each product was scored based on a hedonic evaluation approach from 1 (lowest) to 3 (highest) (Chuarienthong, Lourith, Leelapornpisid, 2010).

Each remover was then subjected to accelerated stability testing by centrifugation at 3,500 rpm for $30 \mathrm{~min}$ (Micromax, Thermo, USA), and seven heat-cool cycles $\left(45 \pm 2{ }^{\circ} \mathrm{C}\right.$ for $48 \mathrm{~h}$ followed by $4 \pm 2{ }^{\circ} \mathrm{C}$ for $48 \mathrm{~h}$ ). The appearance and $\mathrm{pH}$ were examined and compared with the freshly prepared remover (Lourith, Kanlayavattanakul, Chingunpitak, 2017). The para rubber seed oil makeup removers that were stable and scored highly in the qualitative tests were then evaluated for their in vitro cleansing efficacy (Parnsamut et al., 2017) using the validated method previously described.

\section{Statistical analysis}

All data were compared and analyzed using an independent sample $t$ test. The in vitro cleansing efficacy evaluation values and the preference test values were expressed as the mean $\pm \mathrm{RSD}$ and mean $\pm \mathrm{SD}$ (standard deviation), respectively ( $95 \%$ confidence intervals).

\section{RESULTS AND DISCUSSION}

The yield of the oil that was extracted from the para rubber seeds was $19.32 \pm 0.54 \%$, which agrees with the findings of our previous report $(19.02 \pm 0.96 \%)$. The fatty acid profiles of the oils are shown in Figure 1. Oleic and linoleic acids were found to be the major fatty acid substituents of the oil, followed by palmitic and stearic acids. These findings are in strong agreement with our previous study describing the fatty acid content of para rubber oil prepared by Soxhlet extraction with $n$-hexane for the cosmetic industry (Lourith et al., 2014). As a result, we predict that the oil will be non-cytotoxic to cultured cells (Chaikul, Lourith, Kanlayavattanakul, 2017; Lourith et al., 2014), and this para rubber seed oil preparation protocol is standard for industrial practice. Then, we tested the oil for its makeup removal efficacy.

Makeup cosmetics are categorized into base (powder and foundation) and point makeup (eye, lip, and cheek products). Liquid foundation is a base makeup that is mainly applied on the face (Lourith, Kanlayavattanakul, 2014) and is the most commonly used makeup product (Romanowski, 2014).

First, we developed a UV-Vis spectroscopic method to analyze liquid foundation removal. The working wavelength was determined to be $258 \mathrm{~nm}$ (Figure 2A). The linearity of UV-Vis spectroscopic method was established by measuring the absorbance of six replicate samples of the liquid foundation at each concentration of a dilution series at $258 \mathrm{~nm}$. The coefficient of determination was $>$ 0.995 (Figure 2B), indicating that our proposed method

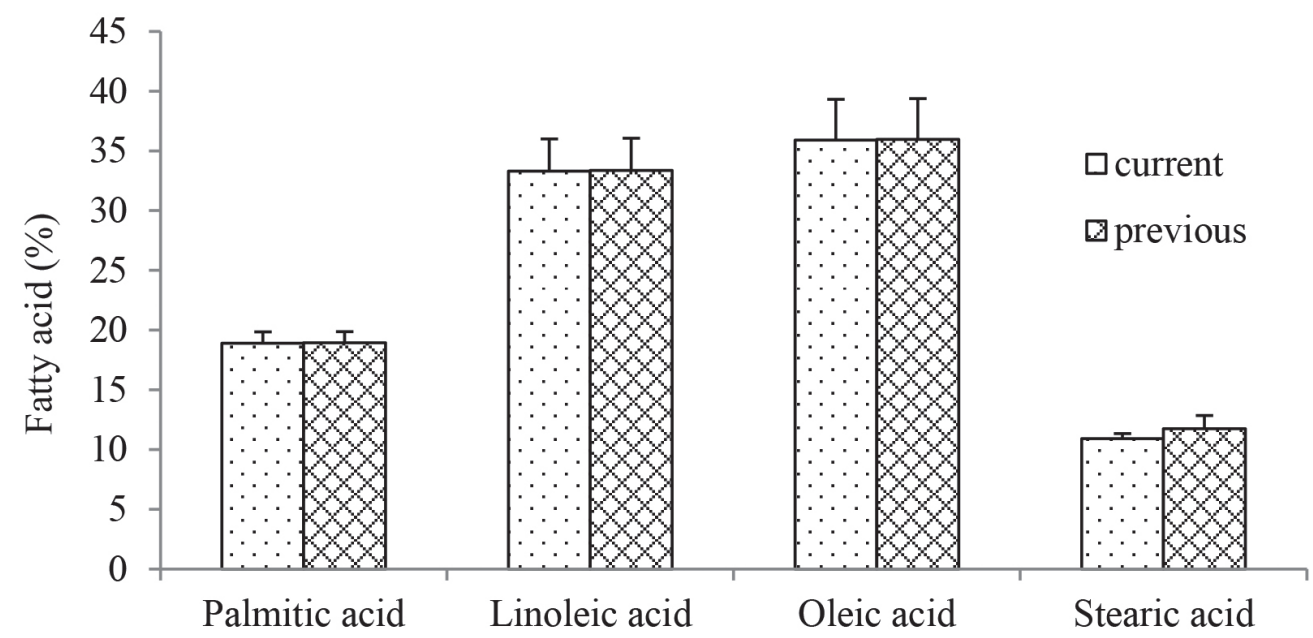

FIGURE 1 - Standardization of para rubber seed oil in terms of fatty acid profiles. 
has a high precision (AOAC, 2002). The validity and reliability of this method was then assessed by calculating the relative standard deviation. The resulting \% RSD confirmed the accuracy of our analytical method [based on USFDA guideline (2001)]. The precision of the analytical method was confirmed by analyzing six replicate samples containing $100 \%$ of the test concentration $(0.7 \mathrm{mg} / \mathrm{mL})$. The results are shown in Table I.

The para rubber seed oil removed $86.21 \pm 2.48 \%$ of the liquid foundation. The precision of the liquid foundation analysis was determined to be within the acceptable range that is specified in the AOAC (2002) and ICH (2005) guidelines, as the recovery was close to $100 \%$ with an RSD of $2.88 \%$. These findings ensure the precision of our method under the same operating conditions over a short interval of time and the inter-assay precision within our laboratory.
Finally, we developed makeup removers containing para rubber seed oil, and the appearance and physicochemical properties of each formulation were characterized (Table II). All the formulated makeup removal products were a clear solution with a yellow hue, and the color was observed to darken in correlation with increasing oil content. The measured $\mathrm{pH}$ values of the formulations were found to be within the acceptable range for cosmetic products (Lourith, Kanlayavattanakul, Chingunpitak, 2017). All the formulations were found to be stable following centrifugation assays and heat-cool cycle accelerated stability tests (Table II).

In the sensory test evaluations, the formulator scored the color, odor, texture, and cleansing performance of each preparation [from 1 (lowest) to 3 (highest)]. The makeup remover with the smallest amount of the biooil was found to be the lowest scoring cleanser. The
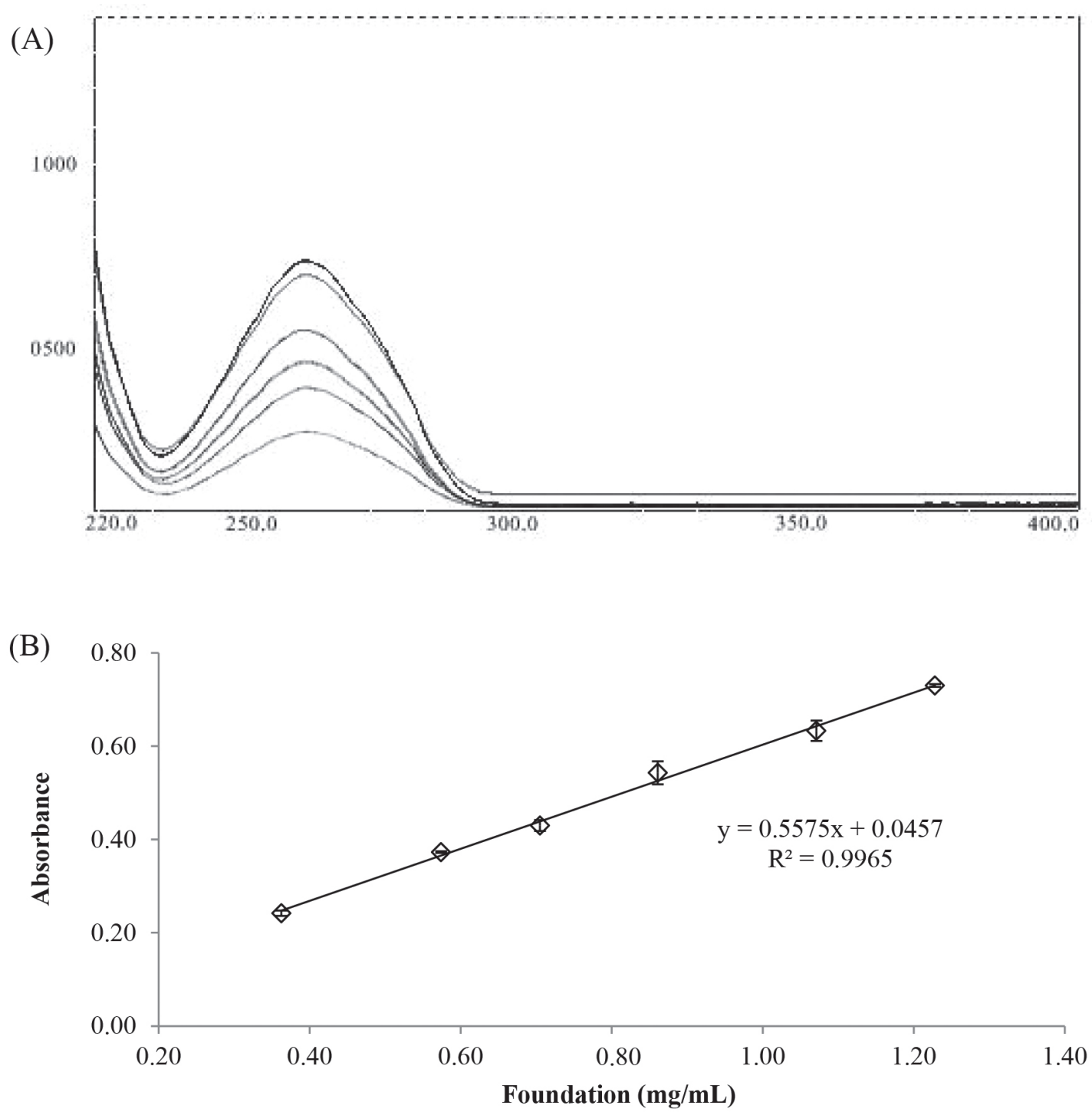

FIGURE 2 - Specificity (A) and standard curve (B) for removal efficacy evaluation against liquid foundation. 
TABLE I - In vitro removal efficacy of para rubber seed oil and makeup removers

\begin{tabular}{lccccc}
\hline \multirow{2}{*}{ Sample } & \multirow{2}{*}{ Absorbance } & \multicolumn{2}{c}{ Amount (mg/mL) } & \multirow{2}{*}{$\begin{array}{c}\text { Cleansing } \\
\text { efficacy (\%) }\end{array}$} & \multirow{2}{*}{ RSD (\%) } \\
\cline { 3 - 5 } & & Add & Found & & \\
\hline Para rubber seed oil & $0.3900 \pm 0.0108$ & $0.7000 \pm 0.0001$ & $0.6030 \pm 0.0174$ & $86.21 \pm 2.48$ & 2.88 \\
Makeup remover & & & & & \\
$\quad 50 \%$ oil & $0.3340 \pm 0.0155$ & & $0.5171 \pm 0.0278$ & $73.88 \pm 3.97$ & 4.64 \\
$\quad 60 \%$ oil & $0.4174 \pm 0.0038$ & & $0.6668 \pm 0.0068$ & $95.26 \pm 0.97$ & 1.01 \\
\hline
\end{tabular}

TABLE II - The components, stability and preference of para rubber seed oil makeup removers

\begin{tabular}{|c|c|c|c|c|}
\hline \multirow{2}{*}{ Ingredient } & \multicolumn{4}{|c|}{ Remover $(\% \mathrm{w} / \mathrm{w})$} \\
\hline & 1 & 2 & 3 & 4 \\
\hline \multicolumn{5}{|l|}{ PEG-20 glyceryl triisostearate } \\
\hline Ethylhexyl palmitate & 39.6 & 39.6 & 39.6 & 29.6 \\
\hline \multicolumn{5}{|c|}{ Neopentyl glycol diheptanoate (and) isododecane } \\
\hline Capric/caprylic triglyceride & 20 & 10 & - & - \\
\hline Tocopheryl acetate & 0.2 & 0.2 & 0.2 & 0.2 \\
\hline Para rubber seed oil & 40 & 50 & 60 & 70 \\
\hline Fragrance & 0.2 & 0.2 & 0.2 & 0.2 \\
\hline Centrifuge assay & \multicolumn{4}{|c|}{ Homogenous } \\
\hline \multicolumn{5}{|l|}{$\mathrm{pH}$} \\
\hline Initial & $5.23 \pm 0.00$ & $5.18 \pm 0.00$ & $4.26 \pm 0.01$ & $4.36 \pm 0.00$ \\
\hline 7 Heat-Cool cycles & $5.12 \pm 0.00$ & $5.16 \pm 0.00$ & $4.91 \pm 0.00$ & $4.66 \pm 0.00$ \\
\hline \multicolumn{5}{|l|}{ Preference } \\
\hline Color & 3 & 3 & 2 & 1 \\
\hline Odor & 2 & 2 & 2 & 1 \\
\hline Texture & 3 & 3 & 3 & 3 \\
\hline Cleansing & 1 & 2 & 2 & 3 \\
\hline Total (12) & 9 & 10 & 9 & 8 \\
\hline
\end{tabular}

preparation with the greatest amount of para rubber seed oil was scored highest for liquid foundation cleansing, but was highly viscous. Based on the total scores for each formulation (resulting in minimum and maximum scores of 4 and 12, respectively), we subsequently assessed the in vitro liquid foundation removal efficacy of the two highest scoring removers.

The makeup remover containing 60\% para rubber seed oil was the best remover with $95.26 \pm 3.97 \%$ cleansing efficacy, which performed significantly $(p<$ 0.001 ) better than pure para rubber seed oil and a $50 \%$ para rubber seed oil formulation (Table I). Further, the cleansing efficacy of the para rubber seed oil remover $(74.92 \pm 2.07 \%$ and $94.48 \pm 3.37 \%$ for oil contents of $50 \%$ and $60 \%$, respectively) was considerably better than the formulated tea seed oil remover previously reported by our laboratory (Parnsamut, Kanlayavattanakul, Lourith, 2017).

\section{CONCLUSIONS}

Hence, we report the transformation of a para rubber by-product into an innovative product for the cosmetic industry. Para rubber seed oil is a novel and promising biooil owing to its safety and biological activity in vitro and ex vivo (Chaikul et al., 2017; Lourith et al., 2014). Makeup removers containing para rubber seed oil are stable and have effective cleansing abilities. Additionally, this new product will broaden the range of consumers' favored biooil containing makeup removers. 
To conclude, makeup removers containing para rubber seed oil represent a potential high-value application of rubber by-product that is feasible for development on an industrial scale.

\section{ACKNOWLEDGEMENTS}

This research was supported financially by the Higher Education Research Promotion Project of Thailand 2015; project number 2559A30762009. Mae Fah Luang University is acknowledged upon facilities supports during this manuscript preparation.

\section{REFERENCES}

AOAC. Guidelines for single laboratory validation of chemical methods for dietary supplements and botanicals; 2002.

Chaikul P, Lourith N, Kanlayavattanakul M. Antimelanogenesis and cellular antioxidant activities of rubber (Hevea brasiliensis) seed oil for cosmetics. Ind Crop Prod. 2017;108:56-62.

Charoennit P, Lourith N. Validated UV-spectrophotometric method for the evaluation of the efficacy of makeup remover. Int J Cosmet Sci. 2012;34(2):190-192.

Chuarienthong P, Lourith N, Leelapornpisid P. Clinical efficacy comparison of anti-wrinkle cosmetics containing herbal flavonoids. Int J Cosmet Sci. 2010;32(2):99-106.

Gandhi VM, Cherian KM, Mulky MJ. Nutritional and toxicological evaluation of rubber seed oil. J Am Oil Chem Soc. 1990;67(11):883-886.

Ikwuagwu OE, Ononogbu IC, Njoku OU. Production of biodiesel using rubber [Hevea brasiliensis (Kunth. Muell.)] seed oil. Ind Crop Prod. 2000;12(1):57-62.

ICH. Validation of analytical procedures: text and methodology Q2(R1); 2005.

Kadir R, Jantan MD. Enhancement of Hevea brasiliensis properties through chemical application. An Acad Bras Cienc. 2016;88(4):2081-2092.
Lourith N, Kanlayavattanakul M. Removal methods and evaluation of removal of makeup products. In: Barel AO, Paye M, Maibach HI (Eds). Handbook of cosmetic science and technology. Florida: CRC; 2014, p. 453-457.

Lourith N, Kanlayavattanakul M, Sucontphunt A, Ondee T. Para rubber seed oil: new promising unconventional oil for cosmetics. J Oleo Sci. 2014;63(7):709-716.

Lourith N, Kanlayavattanakul M, Mongkonpaibool K, Butsaratrakool T, Chinmuang T. Rambutan seed as a new promising unconventional source of specialty fat for cosmetics. Ind Crop Prod. 2016;83:149-154.

Lourith N, Kanlayavattanakul M, Chingunpitak J. Development of sunscreen products containing passion fruit seed extract. Braz J Pharm Sci. 2017;53(1):e16116.

Lourith N, Kanlayavattanakul M, Chaikul P, Chansriniyom C, Bunwatcharaphansakun P. In vitro and cellular activities of the selected fruits residues for skin aging treatment. An Acad Bras Ciênc. 2017;89(Suppl 1):577-589.

Nair KPP. The agronomy and economy of important tree crops of the developing world. Miami: Elsevier; 2010, p. 237-273.

Parnsamut N, Kanlayavattanakul M, Lourith N. Development and efficacy assessments of tea seed oil makeup remover. Ann Pharm Fr. 2017;75(3):189-195.

Ramadhas AS, Jayaraj S, Muraleedharan C. Biodiesel production from high FFA rubber seed oil. Fuel. 2005;84(4):335-340.

Romanowski, S. Five new US products that exemplify the most popular product claim in color cosmetics 2015. 2014. [accessed 20 July 2014]. Available from: http://www.mintel.com/blog/ beauty-market-news/color-cosmetics-trends.

USFDA. Guidance for industry: bioanalytical method validation; 2001.

Received for publication on $11^{\text {th }}$ January 2018 Accepted for publication on $07^{\text {th }}$ January 2019 